\title{
Consumer Perception in the Probability of Buying Luxury Brands: An Abstract
}

\author{
Paula Rodrigues
}

\begin{abstract}
This paper intends to analyse the importance of the perception of the value of luxury in the three dimensions-social, personal and functional-in the probability of buying a luxury brand. For this, a set of constructs is considered by its nature to have these three dimensions: the brand prestige (social value), the brand distinctiveness and the brand attractiveness (social and individual values) and the brand coherence (functional value). The present study follows a quantitative methodology with data collected through an online survey on perceptions of consumers on Chanel brand. The proposal model was estimated using a logistic regression of the probability of buying Chanel considering a set of variables: socio-demographic variables and brand coherence, brand prestige, brand distinctiveness and brand attractiveness. From the results obtained, it was found that the brand prestige and the brand attractiveness increase the likelihood of purchasing Chanel. The sociodemographic variables considered only how income influences the probability of buying the brand. It was demonstrated the importance of the subject, since consumers respond by a buying behaviour if there is a strong attachment to the brand and recognized its prestige and attractiveness.
\end{abstract}

References Available Upon Request

P. Rodrigues ( $₫)$
Lusíada University North, Porto, Portugal
e-mail: pcristinalopesrodrigues@ gmail.com

C Academy of Marketing Science 2019 